\title{
Fractional Flow Assessment for the Evaluation of Intracranial Atherosclerosis: A Feasibility Study
}

\author{
ZhongRong Miao a, c David S. Liebeskind ${ }^{f}$ WaiTing Lo ${ }^{d}$ LiPing Liu ${ }^{b}, c$ \\ YueHua Pu ${ }^{b, c}$ XinYi Lenge LiGang Songa, ${ }^{a}$ XiaoTong $\mathrm{Xu}^{\mathrm{a}, \mathrm{c}}$ BaiXue Jia ${ }^{\mathrm{a}, \mathrm{c}}$ \\ Feng Gao ${ }^{a, c}$ DaPeng Mo ${ }^{a, c}$ Xuan Sun ${ }^{a, c}$ Lian Liua ${ }^{a, c}$ Ning Ma ${ }^{a, c}$ \\ Bo Wang ${ }^{a, c}$ Yilong Wang ${ }^{b, c}$ YongJun Wang ${ }^{b, c}$ \\ Departments of a Interventional Neurology and ${ }^{\mathrm{b}}$ Neurology, Beijing Tiantan Hospital, \\ Capital Medical University, and ${ }^{\mathrm{C} C h i n a ~ N a t i o n a l ~ C l i n i c a l ~ R e s e a r c h ~ C e n t e r ~ f o r ~ N e u r o l o g i c a l ~}$ \\ Diseases, Beijing, and ${ }^{\mathrm{D}}$ Department of Medicine, Queen Elizabeth Hospital, and \\ e Department of Medicine and Therapeutics, The Chinese University of Hong Kong, \\ Hong Kong, SAR, China; ${ }^{f}$ UCLA Stroke Center, Los Angeles, Calif., USA
}

\section{Key Words}

Cerebral ischemia $\cdot$ Fractional flow $\cdot$ Hemodynamics $\cdot$ Stenosis $\cdot$ Stroke

\begin{abstract}
Purpose: Current studies on endovascular intervention for intracranial atherosclerosis select patients based on luminal stenosis. Coronary studies demonstrated that fractional flow measurements assess ischemia better than anatomical stenosis and can guide patient selection for intervention. We similarly postulated that fractional flow can be used to assess ischemic stroke risk. Methods: This was a feasibility study to assess the technical use and safety of applying a pressure guidewire to measure fractional flow across intracranial stenoses. Twenty patients with severe intracranial stenosis were recruited. The percentage of luminal stenosis, distal to proximal pressure ratios (fractional flow) and the fractional flow gradients across the stenosis were measured. Procedural success rate and safety outcomes were documented. $\boldsymbol{R e}$ sults: All 20 patients had successful crossing of stenosis by the pressure guidewire. Ten patients underwent angioplasty, and 5 had stenting performed. There was one perforator stroke, but not related to the use of the pressure wire. For the 13 patients with complete pre- and postintervention data, the mean preintervention stenosis, fractional flow and translesional pressure gradient were $76.2 \%, 0.66$ and $29.9 \mathrm{~mm} \mathrm{Hg}$, whilst the corresponding postintervention measurements were $24.7 \%, 0.88$ and $10.9 \mathrm{~mm} \mathrm{Hg}$, respectively. Fractional flow ( $r=-0.530$, $p=0.001)$ and the translesional pressure gradient $(r=0.501, p=0.002)$ only had a modest correlation with the luminal stenosis. Conclusion: Fractional flow measurement by floating a pressure guidewire across the intracranial stenosis was technically feasible and safe in this study. Further studies are needed to validate its use for ischemic stroke risk assessment.
\end{abstract}




\section{Introduction}

Intracranial atherosclerotic (ICAS) disease is a major cause of stroke worldwide, accounting for $30-50 \%$ of all strokes in Asians [1, 2]. The SAMMPRIS trial showed that even with best medical treatment, the annual stroke recurrence rate for patients with severe intracranial stenosis was as high as $12 \%$ [3]. This same trial, and most recently, the VISSIT trial, did not show benefit from intracranial stenting when compared to best medical treatment [3, 4]. One of the reasons suggested for the lack of benefit was the relative inexperience in the use of the device and in the stenting procedure, leading to mechanical complications $[5,6]$. Another important consideration was whether we are selecting the right patients with the highest recurrent stroke risk, for whom solely best medical treatment alone would not suffice and who might therefore benefit from endovascular intervention.

The selection of patients for ICAS treatment was traditionally based on luminal stenosis. Patients with less than 70\% stenosis had a lower risk of recurrent stroke in the WASID trial [7], and, hence, this patient group was excluded from subsequent large endovascular trials $[3,4]$. However, $40 \%$ of recurrent strokes occurred in patients with $50-69 \%$ stenosis [8]. Recent studies have shown that hemodynamics, collaterals and plaque characteristics are also important factors that should be taken into consideration when evaluating the stroke recurrence risk [9-12]. Coronary studies have shown that functional significant stenosis as assessed by fractional flow (FF) reserve (FFR) determined the ischemic risk better than anatomically defined stenosis. FF can be measured invasively by floating a pressure wire across the lesion. FFR was defined as the maximum achievable blood flow to the myocardium supplied by a stenotic artery as a fraction of the normal maximal flow to the same territory had the artery been completely normal. A cutoff of 0.8 has an accuracy of more than $90 \%$ in discriminating whether the stenosis is associated with significant functional ischemia [13]. FFR-guided percutaneous coronary intervention led to a lower rate of death, myocardial infarction and repeat revascularization when compared to angiographically guided percutaneous coronary intervention $[14,15]$. For patients without a functionally significant stenosis, best medical treatment led to a favorable outcome irrespective of luminal stenosis severity [16]. FFR measurement has now been incorporated as a decision making tool for coronary intervention for both intermediate and severe stenosis of up to $90 \%$ [17-19]. It is also used in renal artery stenosis for the assessment of the need for endovascular intervention [20]. We hypothesize that FF can similarly be used to assess the hemodynamics of intracranial stenosis. Hence, we conducted this study to demonstrate the feasibility of this technique to assess FF across stenotic lesions in the intracranial vasculature.

\section{Methods}

\section{Patients}

Twenty consecutive patients with symptomatic severe intracranial atherosclerotic stenosis considered as potential candidates for endovascular intervention had been recruited between February and March 2015 . Severe intracranial stenosis was defined as a luminal severity of $\geq 70 \%$ on digital subtraction angiography. Of these, $18(90 \%)$ were patients with recurrent strokes. Two patients $(10 \%)$ had intervention considered despite only having had one episode of stroke, as computed tomography perfusion had shown significant hypoperfusion, and computed tomography angiography or magnetic resonance angiography (MRA) had suggested poor collaterals. Patients were excluded if they had a recent infarct within 3 weeks, a modified Rankin Scale score $>2$, a possible nonatherosclerotic cause such as underlying atrial fibrillation or arteritis, or if the target vessel was occluded. The final decision on whether to treat the patient with conservative medical treatment or endovascular means was based on patient symptomatology, anatomical severity of the stenosis, adequacy of collaterals and perfusion status. As we were in the trial phase of using FF with the primary aim to demonstrate technical feasibility, FF was recorded as a reference rather than a guide for intervention. The FF cutoff of 0.8 based on coronary literature was used arbitrarily as a reference. 
Miao et al.: Fractional Flow Assessment for the Evaluation of Intracranial Atherosclerosis: A Feasibility Study
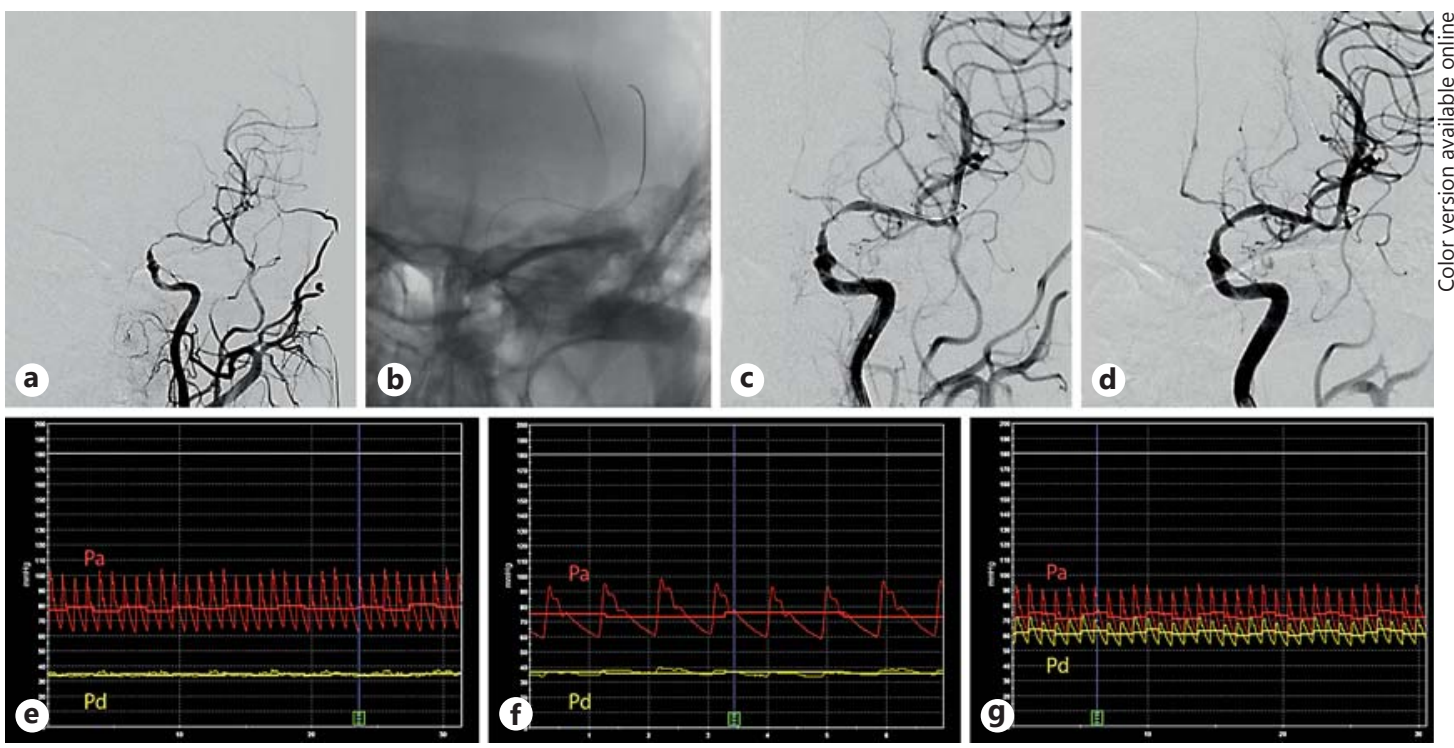

Fig. 1. a A patient with a severe stenosis over the left internal carotid artery C7 segment extending to the M1 segment of the middle cerebral artery, with poor opacification of the left anterior cerebral artery on angiography. b Collateral supply via the leptomeningeal branches and the left posterior communicating artery was suboptimal. A pressure wire was advanced $3 \mathrm{~cm}$ distal to the stenosis to measure the Pd. As there was significant residual stenosis after initial angioplasty with a $1.5 \times 15 \mathrm{~mm}$ Gateway balloon (c), repeat angioplasty was performed with a $2.0 \times 15 \mathrm{~mm}$ Gateway balloon, and a $2.5 \times 15 \mathrm{~mm}$ Wingspan stent was deployed (d). $\mathrm{FF}$ and Pa-Pd gradient were 0.43 and $45 \mathrm{~mm} \mathrm{Hg}$ before intervention (e), 0.49 and $39 \mathrm{~mm} \mathrm{Hg}$ after the first angioplasty (f), and 0.84 and $12 \mathrm{~mm} \mathrm{Hg}$ after final stent deployment (g). The yellow tracing corresponds to $\mathrm{Pd}$, and the red tracing corresponds to Pa. Colors refer to the online version only.

This study with the off-label use of the pressure guidewire had been approved by our institution's ethics committee. It can be used as an auxiliary investigation tool in the following two trials - Wingspan Stenting for Symptomatic Intracranial Artery Stenosis Registry in China (WIRE-China) and Apollo Stenting BalloonMounted Stent for Symptomatic Intracranial Artery Stenosis Registry in China (AIRE-China). Written consent is available for all of the patients.

\section{Endovascular and FF Measurement Technique}

A pressure transducer connected to a 6-Fr guiding catheter was first calibrated in the aorta. The guiding catheter was then advanced distally to a position in the carotid or vertebral artery deemed appropriate for support for intracranial endovascular intervention. The guiding catheter was maintained in this similar position for pressure measurements during the procedure, taking care not to wedge it against the vessel wall. A 0.014-inch pressure wire (PrimeWire Prestige Plus, Volcano, USA) was advanced through the guiding catheter to the catheter's tip. In this position, FF, calculated as the ratio of the distal pressure measured by the pressure wire (Pd) to the aortic pressure measured by the guiding catheter (Pa), should be 1 . Under roadmap guidance, the pressure wire was then negotiated carefully across the lesion until the sensor was about $3 \mathrm{~cm}$ distal to the stenosis, and the $\mathrm{FF}=\mathrm{Pd} / \mathrm{Pa}$ and translesional pressure gradient $=\mathrm{Pa}-\mathrm{Pd}$ were recorded (fig. 1, 2). If the lesion was near a bifurcation, for example the terminal internal carotid artery or the basilar artery, the wire was selected into the larger branch or the less tortuous one. The sensor should not be at or just immediately distal to the stenosis as the pressure measured there may be falsely lower than the actual downstream pressure [21], and it was recommended that the sensor be advanced at least 2-3 cm distal to the lesion [22]. The pressure wire was then used to guide the advancement of angioplasty or stenting devices across the lesion for intervention. For lesions where direct access was considered more difficult, for example the access vessel being tortuous or the vessel caliber being too small, a conventional cerebral microwire (Transend Floppy Tip, 0.014 inch, $300 \mathrm{~cm}$, Stryker, Kalamazoo, Mich., USA) and microcatheter (Echelon-10, ev3, USA) were used to cross the stenosis. The microwire was then exchanged for the pressure 

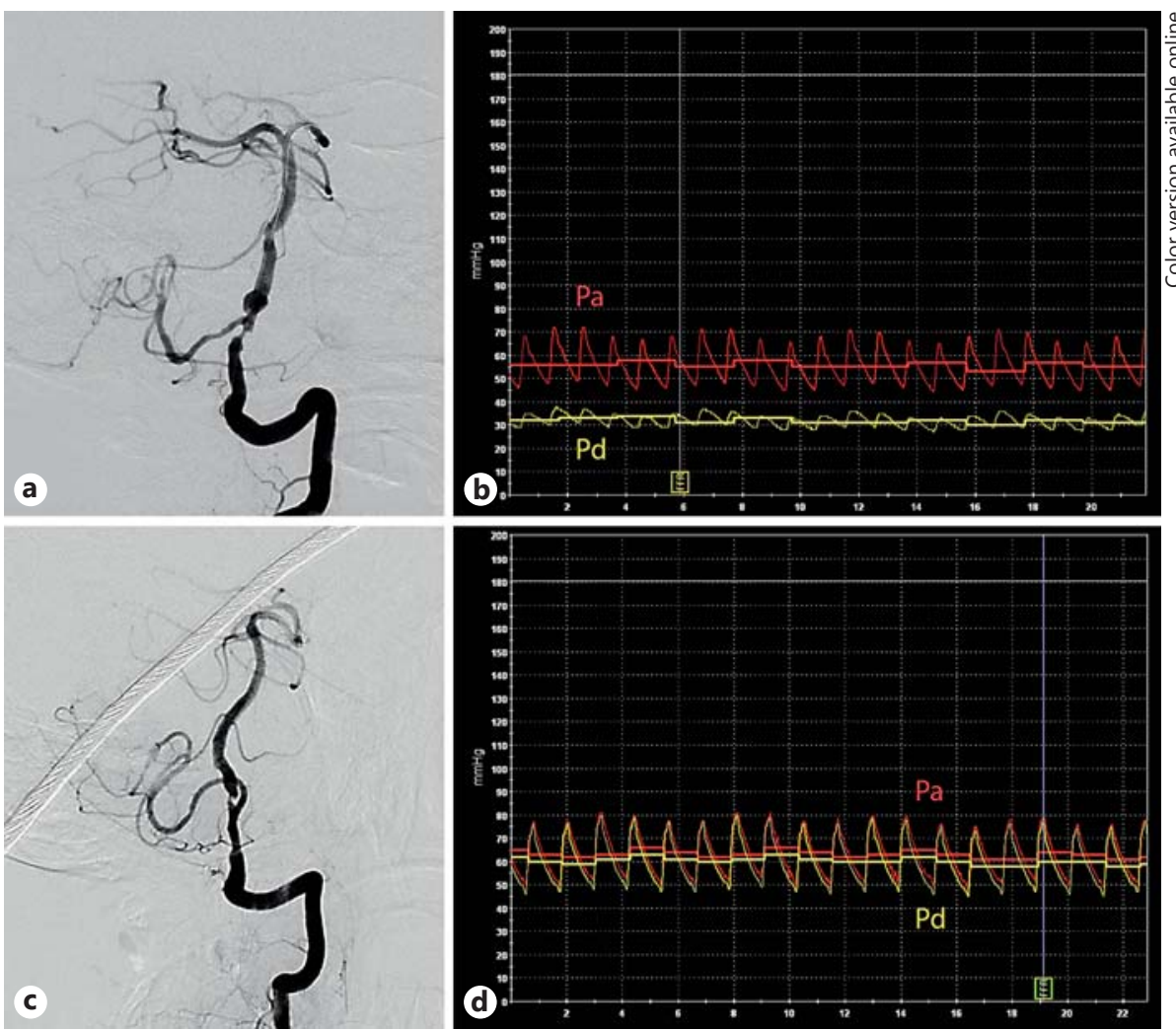

Fig. 2. Two patients with severe LV4 stenosis. For the first patient with severe LV4 stenosis, the right vertebral artery was hypoplastic and terminated at the right PICA (a). Both posterior communicating arteries were nonfunctional; preintervention FF was 0.56, and the translesional Pa-Pd gradient was $24 \mathrm{~mm} \mathrm{Hg}$ (b). Another patient with similar severe LV4 stenosis (c), with bilateral functioning posterior communicating arteries providing good collateral supply; preintervention FF was 0.94, and the translesional Pa-Pd gradient was $4 \mathrm{~mm} \mathrm{Hg}$ (d). The yellow tracing corresponds to Pd, and the red tracing corresponds to Pa. Colors refer to the online version only.

wire, and the microcatheter was withdrawn into the guiding catheter before the Pd was measured. The pressure wire was then exchanged for the conventional microwire, and intracranial intervention proceeded according to usual practices. The choice of endovascular treatment was based on lesion and vessel characteristics [23]. Options include angioplasty alone, stenting with the balloon-mounted Apollo stent (Microport, China) or the self-expandable Wingspan stent (Stryker, USA). After angioplasty or stenting, the pressure wire was again advanced distally to the treated lesion to measure the post-treatment FF and the translesional pressure gradient. The pressure wire was then retrieved into the guiding catheter's tip, and pressure measurements were taken to verify that $\mathrm{Pd}$ was equal to $\mathrm{Pa}$.

Patient demographics, vascular risk factors, degree of intracranial stenosis on digital subtraction angiography based on the WASID criteria [7], presence of tandem lesions and collateral status were recorded. The pressure measurements to study the hemodynamic impact of the stenosis on distal flow were FF and the translesional Pa-Pd pressure gradient. These readings were taken before and after intervention if any. The mode of intervention - best medical treatment, angioplasty alone or stenting - was noted. Procedural success was defined as the successful measurement of FF using the pressure wire. Safety outcomes related to the use of the pressure wire included perforation or intracranial dissection and were recorded if any. Other perioperative complications were also documented.

All of the intracranial endovascular treatments were performed by experienced interventionalists, each carrying out at least 200 intracranial angioplasties or stentings for ICAS disease annually. Patients were put on dual aspirin $100 \mathrm{mg}$ and clopidogrel $75 \mathrm{mg}$ for at least 5 days prior to operation. If not, loading doses were 
Table 1. Basic demographics and treatment of the 20 patients with intracranial stenosis

\section{DOI: $10.1159 / 000444333$}

Miao et al.: Fractional Flow Assessment for the Evaluation of Intracranial Atherosclerosis: A Feasibility Study

\begin{tabular}{|c|c|}
\hline Males & $15(75 \%)$ \\
\hline Mean age $\pm S D$, years & $56 \pm 9.7$ \\
\hline \multicolumn{2}{|l|}{ Vascular risk factors } \\
\hline Hypertension & $13(65 \%)$ \\
\hline Diabetes mellitus & $7(35 \%)$ \\
\hline Hyperlipidemia & $15(79 \%)$ \\
\hline Ischemic heart disease & $2(10 \%)$ \\
\hline Old stroke & $3(15 \%)$ \\
\hline Current smoker & $7(35 \%)$ \\
\hline \multicolumn{2}{|l|}{ Presenting symptoms } \\
\hline Presenting with transient ischemic attacks & $14(70 \%)$ \\
\hline Presenting with stroke & $6(30 \%)$ \\
\hline \multicolumn{2}{|l|}{ Site of intracranial stenosis } \\
\hline Middle cerebral artery M1 segment & $4(20 \%)$ \\
\hline Internal carotid artery C6 or C7 segment & $3(15 \%)$ \\
\hline Basilar artery & $8(40 \%)$ \\
\hline Vertebral artery V4 segment & $5(25 \%)$ \\
\hline \multicolumn{2}{|l|}{ Procedure } \\
\hline General anesthesia & $18(90 \%)$ \\
\hline Use of microcatheter & $13(65 \%)$ \\
\hline \multicolumn{2}{|l|}{ Intervention } \\
\hline Conservative & $5(26.3 \%)$ \\
\hline Angioplasty alone & $10(52.6 \%)$ \\
\hline Stenting & $4(21.1 \%)$ \\
\hline Procedural success in using the pressure wire & $20(100 \%)$ \\
\hline \multicolumn{2}{|l|}{ Technical failure in retrieving the complete set } \\
\hline of results & $2(10 \%)$ \\
\hline Operation technical success & $15 / 15(100 \%)$ \\
\hline Periprocedural complications & $1(5 \%)$ \\
\hline
\end{tabular}

given. Following angioplasty and stenting, all patients underwent an immediate computed tomography scan of the brain. If the computed tomography scan showed no intracerebral hemorrhage, subcutaneous lowmolecular-weight heparin was given for 3 days, dual antiplatelets for at least 3 months, followed by single antiplatelet lifelong.

Statistical analysis was performed with SPSS version 20 (IBM). Continuous variables were expressed as mean \pm SD. Categorical variables were expressed as percentages. Correlation between FF, translesional $\mathrm{Pa}-\mathrm{Pd}$ gradient and percentage of anatomical stenosis were analyzed by Spearman's correlation test. A $\mathrm{p}$ value $<0.05$ was considered statistically significant.

\section{Results}

Baseline demographics and procedural characteristics of the 20 study patients are shown in table 1 . The mean age was 56 years. The sites of intracranial stenosis were the middle cerebral artery M1 segment for 4 patients, the internal carotid artery C6 or C7 segment for 3 patients, the basilar artery for 8 patients and the vertebral artery V4 segment for 5 patients. The mean preoperative stenosis rate for the 20 patients was $75.5 \pm 8.6 \%$. All of the patients had a successful passage of the pressure guidewire across the stenosis; 13 (65\%) had the pressure wire advanced with the assistance of a microcatheter. Eighteen patients (90\%) had both the pre- and post-intervention pressure measurements successfully recorded. One patient did not have the postintervention pressure successfully measured, probably due to water contamination resulting in wire malfunction, and the other patient did not have the full set of readings properly saved in the machine. 
Miao et al: Fractional Flow Assessment for the Evaluation of Intracranial

Fifteen patients were determined to receive angioplasty or stenting, all of whom had the operation successfully performed. Thirteen of them had complete pre- and postintervention measurement data. The mean anatomical stenosis of these lesions was reduced from $76.2 \pm$ 8.3 to $24.7 \pm 11.7 \%$ postoperatively. The mean pre- and postintervention FF and translesional pressure gradient are given in table 2 . The correlation of the severity of the stenosis with FF $(r=-0.530, p=0.001)$ and with the translesional pressure gradient $(r=0.501, p=0.002)$ is shown in figure 3. Anterior and posterior circulation lesions were also analyzed separately. The correlation between stenosis severity and FF $(r=-0.618, p=0.018)$ or translesional pressure gradient $(r=0.465, p=0.094)$ was not strong for anterior circulation lesions. Similarly, for posterior circulation lesions, stenosis severity did not correlate strongly with FF $(\mathrm{r}=-0.510, \mathrm{p}=0.015)$ or the translesional pressure gradient $(\mathrm{r}=0.487, \mathrm{p}=0.021)$ either. Postoperatively, 1 patient with LV4 stenosis had a perforator stroke with symptoms of mild left ataxia; the patient could walk unaided on discharge a few days later. There were no complications related to the use of the pressure guidewire.

\section{Discussion}

FF hemodynamic measurement reflects the impact of a stenosis on downstream perfusion better than the percentage of luminal stenosis [13]. For any intervention to be considered beneficial, optimal selection of patients with the highest risk for nonintervention and exclusion of lower-risk patients for whom sole medical treatment would suffice is imperative. Inclusion of lower-risk patients into studies would dilute out any possible effect of benefit from the treatment. The coronary and renal communities have both walked through the path from initial negative trials based on luminal stenosis $[24,25]$ to positive trials based on FF assessment of the stenosis [14-16, 26]. Our study is the first study to use intracranial FF measurement with a pressure guidewire for the assessment of the intracranial atherosclerosis.

The present case series demonstrated technical feasibility of using a pressure wire to measure $\mathrm{FF}$ in the cerebral vasculature for the assessment of intracranial stenosis. One concern was the possibility of the microcatheter partially obstructing the blood flow affecting pressure measurements. We retrieved the microcatheter into the guiding catheter when we measured Pd and found that the presence of the microcatheter did not significantly affect the pressure readings. Thirteen patients had tortuous access or small-caliber vessels. With the use of the microcatheters, none of the patients had complications related to the use of the pressure wire, demonstrating the safety of this approach in our study patients. There was one perforator stroke unrelated to pressure wire use in a patient with the high risk factors of diabetes and initial presentation being a perforator stroke. There was no intracranial dissection or perforation of vessels. The use of pressure wires had also been reported in case reports to assess the hemodynamics of cerebral aneurysms and arteriovenous malformation $[27,28]$. These case reports and our study suggested that with careful manipulation and the use of microcatheters and exchange maneuvers, if necessary, measurement of FF in even small intracranial vessels can be performed safely. Two patients had FF measurement performed under local anesthesia. Both tolerated the procedure.

In this preliminary study, in which all patients had severe anatomical stenosis $\geq 70 \%$, FF and the translesional pressure gradient only showed a modest correlation with stenosis severity (fig. 3). This was in line with previous coronary and renal studies which did not show a strong correlation between functional and anatomical stenosis [20, 29]. In the SAMMPRIS trial, only $40 \%$ of the patients with $>70 \%$ luminal stenosis had hemodynamic significant stenosis on computer fluid dynamics (CFD) analysis [30]. These findings were not surprising 
Miao et al.: Fractional Flow Assessment for the Evaluation of Intracranial Atherosclerosis: A Feasibility Study

Fig. 3. Scatterplot showing the relationship between the percentage of stenosis and FF (a) and the relationship between the percentage of stenosis and the translesional Pa-Pd gradient (b).

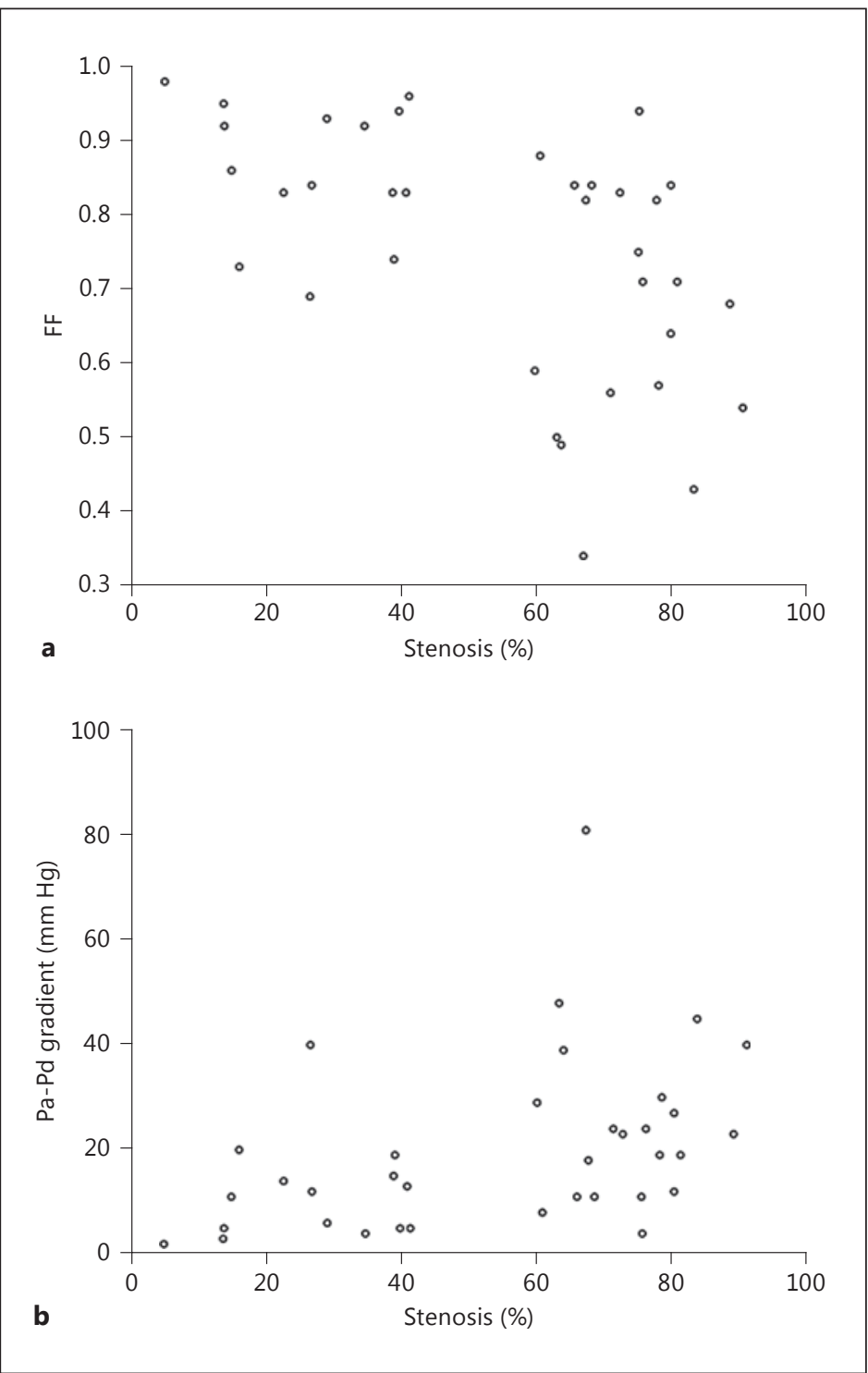

Table 2. Stenosis, FF and translesional pressure gradient before and after intervention

\begin{tabular}{|c|c|c|c|c|}
\hline & \multicolumn{2}{|c|}{ Before intervention } & \multicolumn{2}{|c|}{ After intervention } \\
\hline & $\begin{array}{l}\text { all patients } \\
(\mathrm{n}=19)^{\mathrm{a}}\end{array}$ & $\begin{array}{l}\text { patients with } \\
\text { PTA or stenting } \\
(\mathrm{n}=13)^{\mathrm{b}}\end{array}$ & $\begin{array}{l}\text { patients with } \\
\text { PTA or stenting } \\
(\mathrm{n}=13)^{\mathrm{b}}\end{array}$ & $\begin{array}{l}\text { patients on conser- } \\
\text { vative management } \\
(n=5)\end{array}$ \\
\hline Stenosis, \% & $74.8 \pm 8.3$ & $76.2 \pm 8.3$ & $24.7 \pm 11.7$ & $70.1 \pm 7.7$ \\
\hline $\mathrm{FF}$ & $0.70 \pm 0.17$ & $0.66 \pm 0.18$ & $0.88 \pm 0.09$ & $0.79 \pm 0.12$ \\
\hline Pa-Pd gradient, mm Hg & $25.6 \pm 17.9$ & $29.9 \pm 19.8$ & $10.9 \pm 10.3$ & $15.8 \pm 8.9$ \\
\hline
\end{tabular}

PTA $=$ Percutaneous transluminal angioplasty. Figures are presented as mean \pm SD. ${ }^{\text {a }} 1$ patient had incomplete preintervention data, hence his data were not presented in this table. ${ }^{\mathrm{b}} 1$ more patient had incomplete postintervention pressure measurements due to technical issues with the machine, and not due to the patient or the procedure, hence his data were also not included in this table. 
Miao et al: Fractional Flow Assessment for the Evaluation of Intracranial

as functional ischemia was also influenced by collaterals, vessel wall and plague characteristics. The patients presented in figure 2 illustrated that even with similar anatomical severity, the FF across a lesion was higher with better collateral flow and lower when collateral flow was inadequate. With $\mathrm{FF}$, we now potentially have a means to quantify and study the impact of collaterals on downstream blood flow. However, the number of patients in our study was not large enough to do a meaningful comparison of patients with or without good collaterals. We also did not have any patients with severe tandem stenosis to study the effect of proximal vessel stenosis on distal flow pressure measurement. Further studies would be needed.

This feasibility study on the use of FF for intracranial atherosclerosis clears the way for noninvasive validation of FF measures and for a preprocedural validation prior to potential intervention. The results based on coronary ratios are reasonable approximations in the cerebral circulation. With refinement of techniques and ascertainment of a cutoff value to define significant functional ischemia, FF can act as one of the tools to select appropriate patients for intervention, and guide how to intervene intraoperatively - by angioplasty alone or whether additional stenting is needed. Currently, FF measurements can only be deduced from CFD studies or change of signal intensities on MRA. Leng et al. [31] demonstrated on CFD models that the translesional pressure gradient has a trend towards being able to predict recurrent ischemic stroke risk in the territory of the treated artery within 1 year. Liebeskind et al. [32] reported that the use of the signal intensity ratio index, calculated from the change of signal intensities based on flow-related contrast enhancement on time-of-flight MRA images, was associated with recurrent stroke in the territory of the stenotic artery, irrespective of the anatomical stenosis severity. These noninvasive methods, though attractive, are also in the initial phase of development and are not without their own limitations. Neither CFD nor MRA can produce real-time assessment of the effects of angioplasty and stenting on the flow hemodynamics during the operation to guide treatment decision-making. CFD is based on theoretical modelling and has not been validated against invasive pressure measurements, and the effect of blood pressure changes or blood flow through an extremely severe stenosis may not be properly simulated. The MRA-signal intensity ratio index for near-occlusions may not be reliably estimated. The need for sophisticated processing for advanced MRA imaging and calculation, and geometric reconstruction for CFD make these techniques not yet widely applicable in clinical practice.

\section{Limitations}

We recognize that we cannot directly transfer the results of hemodynamic studies from coronary intervention to cerebral intervention without further validation studies. We used the term FF distinctly from FFR or iFR (instant wave-free ratio) as applied in coronary studies. In the initial landmark FFR studies, the coronary microcirculation bed in the myocardium was dilated by infusion of vasodilatory agents such as adenosine to minimize resistance so that the pressure measurement could reflect flow. However, induction of hyperemia was not needed in later iFR studies making use of the observation that pressure has a linear relationship with flow during a phase in the diastole without intracoronary pressure being affected by myocardial contractility [33]. Intracranial vessels are surrounded by cerebrospinal fluid rather than embedded in the muscle, and the vessel wall structure, cerebral autoregulation and recruitment of collaterals are different from coronary vessels. Further studies and the correlation with noninvasive studies are needed to investigate how cerebral autoregulation will affect pressure and flow across a stenotic vessel, and whether the location of the lesion in the circle of Willis will affect interpretation. Moreover, the mechanism of ischemia in ICAS disease is multifactorial; thus, hemodynamic assessment constitutes only a part of the stroke risk assessment. Our study was aimed to demonstrate technical feasibility of FF measurement, rather than to establish a cerebral ischemic criterion, or to propose FF as the 
Miao et al: Fractional Flow Assessment for the Evaluation of Intraciani

Atherosclerosis: A Feasibility Study

sole assessment tool. We had not recruited any patients with $<70 \%$ stenosis in our pilot study; FF was rather measured as an ancillary investigational tool in our patients with severe stenosis considered for possible intervention based on anatomical stenosis. It is possible that by limiting FF study to patients with severe anatomical stenosis, we are missing a group of patients with a high functional ischemic risk albeit having only a moderate stenosis. In renal studies, the translesional pressure gradient was used to guide intervention for renal artery stenosis [20]. Further studies would be needed to clarify which parameter in FF assessment is most appropriate as well as the optimal cutoff value to identify cerebral ischemic stroke risk.

The Volcano pressure wire used in this study was originally manufactured for coronary use; thus, careful assessment of the intracranial vasculature and the lesion before intervention is needed. As with any interventional operations, experience in intracranial procedures and devices leads to lower complication rates. A microcatheter and a microwire manufactured specifically for intracranial use with better steerability and torqueability should first be used to cross the lesion if access to the lesion is tortuous. If pressure wires specifically tailored for intracranial vasculature can be available, which can also act as the microwire for cerebral endovascular intervention, then the risk and the length of time for pressure measurement can be reduced.

\section{Conclusion}

Experience from coronary studies has shown that the functional severity of a stenosis correlates with ischemic symptoms and recurrence better than the anatomical severity. We believe that similarly, FF measurement has the potential to be a useful biomarker to assess the functional significance of a stenotic lesion to downstream perfusion. Future studies with a longer follow-up, together with the knowledge gained from emerging noninvasive techniques, would be needed to determine an optimal cutoff for defining ischemic risk and to validate this method to select patients for intervention and guide intraoperative decisionmaking.

\section{Disclosure Statement}

We declare no conflicts of interest.

\section{References}

1 Gorelick PB, Wong KS, Bae HJ, Pandey DK: Large artery intracranial occlusive disease: a large worldwide burden but a relatively neglected frontier. Stroke 2008;39:2396-2399.

2 Wang Y, Zhao X, Liu L, Soo YO, Pu Y, Pan Y, Wang Y, Zou X, Leung TW, Cai Y, Bai Q, Wu Y, Wang C, Pan X, Luo B, Wong KS; CICAS Study Group: Prevalence and outcomes of symptomatic intracranial large artery stenoses and occlusions in China: the Chinese Intracranial Atherosclerosis (CICAS) Study. Stroke 2014;45:663-669.

3 Chimowitz MI, Lynn MJ, Derdeyn CP, Turan TN, Fiorella D, Lane BF, Janis LS, Lutsep HL, Barnwell SL, Waters MF, Hoh BL, Hourihane JM, Levy EI, Alexandrov AV, Harrigan MR, Chiu D, Klucznik RP, Clark JM, McDougall CG, Johnson MD, Pride GL Jr, Torbey MT, Zaidat OO, Rumboldt Z, Cloft HJ; SAMMPRIS Trial Investigators: Stenting versus aggressive medical therapy for intracranial arterial stenosis. N Engl J Med 2011;365:993-1003.

4 Zaidat OO, Fitzsimmons BF, Woodward BK, Wang Z, Killer-Oberpfalzer M, Wakhloo A, Gupta R, Kirshner H, Megerian JT, Lesko J, Pitzer P, Ramos J, Castonguay AC, Barnwell S, Smith WS, Gress DR; VISSIT Trial Investigators: Effect of a balloon-expandable intracranial stent vs medical therapy on risk of stroke in patients with symptomatic intracranial stenosis: the VISSIT randomized clinical trial. JAMA 2015;313:1240-1248.

5 Leung TW, Yu SC, Wong KS: Have medical therapy and stenting been fairly compared? A repercussion upon termination of recruitment in the SAMMPRIS trial. Int J Stroke 2011;6:312-314. 
6 von Schoenfeldt P, Krützelmann A, Bussmeyer M, Mpotsaris A, Rosenkranz M, Fiehler J, Weber W, Buhk JH: Elective treatment of intracranial stenosis with the balloon-expandable Pharos Vitesse stent: 30-day stroke rate and complications. J Neurointerv Surg 2015; 7:188-193.

7 Chimowitz MI, Lynn MJ, Howlett-Smith H, Sila CA, Jovin TG, Romano JG; Warfarin-Aspirin Symptomatic Intracranial Disease Trial Investigators: Comparison of warfarin and aspirin for symptomatic intracranial arterial stenosis. N Engl J Med 2005;352:1305-1316.

8 Kasner SE, Chimowitz MI, Lynn MJ, Howlett-Smith H, Stern BJ, Hertzberg VS, Frankel MR, Levine SR, Chaturvedi S, Benesch CG, Sila CA, Jovin TG, Romano JG, Cloft HJ; Warfarin Aspirin Symptomatic Intracranial Disease Trial Investigators: Predictors of ischemic stroke in the territory of a symptomatic intracranial arterial stenosis. Circulation 2006;113:555-563.

9 Leng X, Wong KS, Liebeskind DS: Evaluating intracranial atherosclerosis rather than intracranial stenosis. Stroke 2014;45:645-651.

10 Liebeskind DS, Cotsonis GA, Saver JL, Lynn MJ, Turan TN, Cloft HJ, Chimowitz MI; Warfarin-Aspirin Symptomatic Intracranial Disease (WASID) Investigators: Collaterals dramatically alter stroke risk in intracranial atherosclerosis. Ann Neurol 2011;69:963-974.

11 Bodle JD, Feldmann E, Swartz RH, Rumboldt Z, Brown T, Turan TN: High-resolution magnetic resonance imaging: an emerging tool for evaluating intracranial arterial disease. Stroke 2013;44:287-292.

12 Alexander MD, Cooke DL, Meyers PM, Amans MR, Dowd CF, Halbach VV, Higashida RT, Hetts SW: Lesion stability characteristics outperform degree of stenosis in predicting outcomes following stenting for symptomatic intracranial atherosclerosis. J Neurointerv Surg 2016;8:19-23.

13 Pijls NH, Tanaka N, Fearon WF: Functional assessment of coronary stenoses: can we live without it? Eur Heart J 2013;34:1335-1344.

14 Tonino PA, De Bruyne B, Pijls NH, Siebert U, Ikeno F, van't Veer M, Klauss V, Manoharan G, Engstrøm T, Oldroyd KG, Ver Lee PN, MacCarthy PA, Fearon WF; FAME Study Investigators: Fractional flow reserve versus angiography for guiding percutaneous coronary intervention. N Engl J Med 2009;360:213-224.

15 De Bruyne B, Fearon WF, Pijls NH, Barbato E, Tonino P, Piroth Z, Jagic N, Mobius-Winckler S, Rioufol G, Witt N, Kala P, MacCarthy P, Engström T, Oldroyd K, Mavromatis K, Manoharan G, Verlee P, Frobert O, Curzen N, Johnson JB, Limacher A, Nüesch E, Jüni P; FAME 2 Trial Investigators: Fractional flow reserve-guided PCI for stable coronary artery disease. N Engl J Med 2014;371:1208-1217.

16 Pijls NH, van Schaardenburgh P, Manoharan G, Boersma E, Bech JW, van't Veer M, Bär F, Hoorntje J, Koolen J, Wijns W, de Bruyne B: Percutaneous coronary intervention of functionally nonsignificant stenosis: 5-year follow-up of the DEFER Study. J Am Coll Cardiol 2007;49:2105-2111.

17 Task Force Members; Montalescot G, Sechtem U, Achenbach S, et al; ESC Committee for Practice Guidelines; Zamorano JL, Achenbach S, Baumgartner H, et al; Document Reviewers; Knuuti J, Valgimigli M, Bueno H, et al: 2013 ESC guidelines on the management of stable coronary artery disease: the Task Force on the management of stable coronary artery disease of the European Society of Cardiology. Eur Heart J 2013;34:2949-3003.

18 Levine GN, Bates ER, Blankenship JC, Bailey SR, Bittl JA, Cercek B, Chambers CE, Ellis SG, Guyton RA, Hollenberg SM, Khot UN, Lange RA, Mauri L, Mehran R, Moussa ID, Mukherjee D, Nallamothu BK, Ting HH: 2011 ACCF/ AHA/SCAI Guideline for Percutaneous Coronary Intervention. A report of the American College of Cardiology Foundation/American Heart Association Task Force on Practice Guidelines and the Society for Cardiovascular Angiography and Interventions. J Am Coll Cardiol 2011;58:e44-e122.

19 Lotfi A, Jeremias A, Fearon WF, Feldman MD, Mehran R, Messenger JC, Grines CL, Dean LS, Kern MJ, Klein LW; Society of Cardiovascular Angiography and Interventions: Expert consensus statement on the use of fractional flow reserve, intravascular ultrasound, and optical coherence tomography: a consensus statement of the Society of Cardiovascular Angiography and Interventions. Catheter Cardiovasc Interv 2014;83:509-518.

20 Mangiacapra F, Trana C, Sarno G, Davidavicius G, Protasiewicz M, Muller O, Ntalianis A, Misonis N, Van Vlem B, Heyndrickx GR, De Bruyne B: Translesional pressure gradients to predict blood pressure response after renal artery stenting in patients with renovascular hypertension. Circ Cardiovasc Interv 2010;3:537-542.

21 Seto AH, Tehrani D, Kern MJ: Limitations and pitfalls of fractional flow reserve measurements and adenosineinduced hyperemia. Intervent Cardiol Clin 2015;4:419-434.

22 Vranckx P, Cutlip DE, McFadden EP, Kern MJ, Mehran R, Muller O: Coronary pressure-derived fractional flow reserve measurements: recommendations for standardization, recording, and reporting as a core laboratory technique. Proposals for integration in clinical trials. Circ Cardiovasc Interv 2012;5:312-317.

23 Miao Z, Song L, Liebeskind DS, Liu L, Ma N, Wang Y, Mo D, Gao F, Zhao X, Dong K, Zhang D, Gao P: Outcomes of tailored angioplasty and/or stenting for symptomatic intracranial atherosclerosis: a prospective cohort study after SAMMPRIS. J Neurointerv Surg 2015;7:331-335.

24 Boden WE, O’Rourke RA, Teo KK, Hartigan PM, Maron DJ, Kostuk WJ, Knudtson M, Dada M, Casperson P, Harris CL, Chaitman BR, Shaw L, Gosselin G, Nawaz S, Title LM, Gau G, Blaustein AS, Booth DC, Bates ER, Spertus JA, Berman DS, Mancini GB, Weintraub WS; COURAGE Trial Research Group: Optimal medical therapy with or without PCI for stable coronary disease. N Engl J Med 2007;356:1503-1516.

25 BARI 2D Study Group; Frye RL, August P, Brooks MM, Hardison RM, Kelsey SF, MacGregor JM, Orchard TJ, Chaitman BR, Genuth SM, Goldberg SH, Hlatky MA, Jones TL, Molitch ME, Nesto RW, Sako EY, Sobel BE: A randomized trial of therapies for type 2 diabetes and coronary artery disease. N Engl J Med 2009;360:25032515. 
Miao et al.: Fractional Flow Assessment for the Evaluation of Intracranial Atherosclerosis: A Feasibility Study

26 Layland J, Oldroyd KG, Curzen N, Sood A, Balachandran K, Das R, Junejo S, Ahmed N, Lee MM, Shaukat A, O’Donnell A, Nam J, Briggs A, Henderson R, McConnachie A, Berry C; FAMOUS-NSTEMI investigators: Fractional flow reserve vs angiography in guiding management to optimize outcomes in non-ST-segment elevation myocardial infarction: the British Heart Foundation FAMOUS-NSTEMI randomized trial. Eur Heart J 2015;36: 100-111.

27 Ferns SP, Schneiders JJ, Siebes M, van den Berg R, van Bavel ET, Majoie CB: Intracranial blood-flow velocity and pressure measurements using an intra-arterial dual-sensor guidewire. AJNR Am J Neuroradiol 2010;31: 324-326.

28 Orlov K, Panarin V, Krivoshapkin A, Kislitsin D, Berestov V, Shayakhmetov T, Gorbatykh A: Assessment of periprocedural hemodynamic changes in arteriovenous malformation vessels by endovascular dual-sensor guidewire. Interv Neuroradiol 2015;21:101-107.

29 Tonino PA, Fearon WF, De Bruyne B, Oldroyd KG, Leesar MA, Ver Lee PN, Maccarthy PA, van't Veer M, Pijls NH: Angiographic versus functional severity of coronary artery stenoses in the FAME study fractional flow reserve versus angiography in multivessel evaluation. J Am Coll Cardiol 2010;55:2816-2821.

30 Liebeskind DS, Fong AK, Scalzo F, Lynn MJ, Derdeyn CP, Fiorella DJ, Cloft HJ, Chimowitz MI, Feldmann E; SAMMPRIS Investigators: SAMMPRIS angiography discloses hemodynamic effects of intracranial stenosis: computational fluid dynamics of fractional flow. Stroke 2013;44:A156.

31 Leng X, Scalzo F, Ip HL, Johnson M, Fong AK, Fan FS, Chen X, Soo YO, Miao Z, Liu L, Feldmann E, Leung TW, Liebeskind DS, Wong KS: Computational fluid dynamics modeling of symptomatic intracranial atherosclerosis may predict risk of stroke recurrence. PLoS One 2014;9:e97531.

32 Liebeskind DS, Kosinski AS, Lynn MJ, Scalzo F, Fong AK, Fariborz P, Chimowitz MI, Feldmann E: Noninvasive fractional flow on MRA predicts stroke risk of intracranial stenosis. J Neuroimaging 2015;25:87-91.

33 Sen A, Petraco R, Nijjer S, Mayet J, Davies J: Can resting indices obviate the need for hyperemia and promote the routine use of physiologically guided revascularization? Intervent Cardiol Clin 2015;4:459-469. 